\title{
HUBUNGAN PENGGUNAAN SEPATU BOOT DAN PREVALENSI Trichophyton sp PADA PENAMBANG BATU BARA
}

\author{
Suhartini*1), Ganea Qorry Aina $^{2)}$, Famala Eka Sanhadi Rahayu ${ }^{3)}$ \\ 1,2 D-III Teknologi Laboratorium Medik, Jurusan Teknologi Laboratotium Medik, Poltekkes Kemenkes \\ Kalimantan Timur, Samarinda, Indonesia \\ 3 DS-1 Sastra Inggris, Fakultas Ilmu Budaya, Universitas Mulawarman, Samarinda, Indonesia \\ email: suhartini@poltekkes-kaltim.ac.id
}

\begin{abstract}
Abstrak
Tinea unguium merupakan kelainan kuku yang disebabkan oleh jamur golongan dermatofita terutama genus Trichophyton sp. Penyakit ini sering menyerang penambang batu bara yang selalu menggunakan sepatu tertutup saat bekerja dalam waktu yang lama, menyebabkan kondisi kaki lembab sehingga merupakan media potensial untuk pertumbuhan jamur. Tujuan penelitian ini adalah mengetahui hubungan lama penggunaan sepatu terhadap prevalensi Tricophyton sp. Merupakan penelitian korelasional dengan desain univariat, mengidentifikasi jamur pada kerokan kuku 40 pekerja tambang batu bara di Kelurahan Loa Janan Ulu dengan durasi bekerja sebagai penambang batu bara. Hasil penelitian ditemukan jamur penyebab tinea unguium dari genus Trichophyton sebanyak 34 sampel (85\%), sebanyak 6 sampel (15\%) hanya ditemukan jamur non dermatofita seperti Aspergillus sp, Penicillium sp, Cylindrocapon sp, Cladophialophora sp, Mucor $s p$, Penicillium sp, Fusarium sp, dan Curvularia sp. Hasil penelitian menunjukkan korelasi signifikan dengan koefisien korelasi sebesar 0,931 sehingga ada korelasi yang kuat antara durasi penggunaaan sepatu safety dengan prevalensi infeksi Tricophyton sp. Pekerja tambang yang positif (34 sampel) rata-rata bekerja lebih dari 12 jam per hari dan 6 sampel lainnya bekerja 2-4 jam sehari. Kesimpulan terdapat korelasi antara lama penggunaan sepatu dengan prevalensi Tricophyton sp pada pekerja tambang. Saran mengidentifikasi sampai tingkat jenis jamur Tricophyton sp yang menginfeksi kuku pekerja tambang.
\end{abstract}

Kata kunci : Tinea unguium, Sepatu Safety, Pekerja Tambang Batu Bara.

\begin{abstract}
Tinea unguium is an infection of the nail plate caused by dermatophyta fungi especially Trichophyton sp. This infection commonly affects coal miners who wears safety boots in long duration which makes their feet humid and become a potential media for fungi to grow. This study aims to investigate how duration of wearing boots correlate with Tricophyton $s p$ prevalence. This study employed a univariate-correlational design to correlate Tricophyton sp prevalence in toenails sample taken from 40 coal miners in Loa Janan Ulu District with their working duration. The finding of this study reveals that 34 samples (85\%) are infected by Trichophyton sp while on the other hand, it is found a non dermatophyta fungi such Aspergillus $s p$, Penicillium sp, Cylindrocapon sp, Cladophialophora sp, Mucor sp, Penicillium sp, Fusarium sp, dan Curvularia sp in 6 sampes. It reveals that $R$ value is 0,931 and therefore it concludes that there is a significant correlation between duration of wearing boots and Tricophyton sp prevalence in coal miners. Looking at the duration, 34 infected samples belong to coal miners who works more than 12 hours a day while the other six works for two until four hours per day. This study concludes that there is a correlation between duration of using safety boots and the Tricophyton prevalence in coal miner's nails. The present researchers suggest the future researcher to identify the types of Tricophyton fungi which infected coal miner's nails.
\end{abstract}

Keywords: : Tinea unguium, Safety Boots, Coal Miners

\section{PENDAHULUAN}

Jamur merupakan salah satu penyebab infeksi pada penyakit terutama di negara- negara tropis. Infeksi jamur merupakan penyakit yang sering muncul di tengah masyarakat Indonesia, karena Indonesia merupakan salah satu negara yang beriklim 
tropis dengan kelembapan udara yang tinggi, kondisi tersebut merupakan suasana yang baik bagi pertumbuhan jamur. Sebagian jamur bersifat patogen pada manusia dan selebihnya merupakan jamur komensal yang hidup sebagai saprofit pada manusia (Rahman et al., 2016).

Pada manusia, dapat terjadi penyakit yang disebabkan oleh jamur yaitu yang disebut dengan mikosis. Mikosis dapat dikelompokkan beberapa kelompok yaitu superfisial (menginfeksi lapisan luar kulit, rambut, dan kuku), kutaneus (menginfeksi lapisan epidermis yang memiliki kreatin), subkutaneus (menginfeksi hingga lapisan dermis), dan oportunistik (menginfeksi apabila system kekebalan tubuh tidak seimbang). Dari beberapa kelompok penyakit yang disebabkan oleh jamur tersebut menggambarkan bagaimana terjadinya infeksi jamur (Brooks et al., 2012).

Di Indonesia salah satu wilayah yang terdapat penyakit infeksi jamur yaitu Provinsi Kalimantan Timur khususnya Samarinda. Kasus infeksi jamur yang diperoleh pada bulan Mei 2016 dari Dinas Kesehatan Kota Samarinda menunjukkan dari tahun 2013 sampati tahun 2015 menunjukkan peningkatan dari penyakit yang disebabkan oleh jamur. Data yang diperoleh dari Dinas Kesehatan kota Samarinda pada tahun 2013 menunjukkan bahwa terdapat 68 kasus penyakit yang disebabkan oleh jamur. Data yang diperoleh dari Dinas Kesehatan pada tahun 2014 berdasarkan jenis kelamin yaitu terdapat 17 kasus penyakit yang disebabkan oleh jamur. Pada tahun berikutnya data dari Dinas Kesehatan tahun 2015 menunjukkan terdapat 699 kasus penyakit infeksi jamur. Dari data tersebut, diketahui bahwa tingkat penyakit yang disebabkan oleh jamur masih tinggi (Pravitasari et al., 2019).

Lingkungan kerja merupakan tempat yang potensial mempengaruhi kesehatan pekerja. Salah satu penyakit yang dapat ditimbulkan akibat lingkungan kerja yaitu infeksi jamur atau mikosis superfisial. Bila dihubungkan dengan jenis pekerjaan, mikosis superfisial dapat terjadi pada semua pekerjaan, terutama pada pekerja yang menggunakan alat pelindung diri yang kedap udara dengan pemakaian waktu yang lama, misalnya seperti sepatu safety (Rahman et al., 2016). Pekerja yang menggunakan sepatu safety antara lain petugas kebersihan, anggota brimob, dan pekerja tambang. Penggunaan sepatu yang tertutup dan kedap udara saat bekerja akan menimbulkan kelembaban pada kaki dimana keadaan ini dapat menjadi media potensial pertumbuhan jamur pada kuku kaki, Terdapat tiga genus penyebab dermatofitosis, yaitu microsporum, trichophyton, dan epidermophyton. Golongan jamur Trichophyton dan Epidermophyton lebih sering mengakibatkan infeksi kuku dibandingkan jamur golongan microsporum (Irianto, 2013).

Kelainan pada kuku yang disebabkan oleh infeksi jamur disebut onikomikosis. Onikomikosis diperkirakan mencakup lebih dari $50 \%$ kelainan kuku dan merupakan kelainan kuku paling sering (Welsh et al, 2010).Khusus untuk infeksi jamur pada kuku yang disebabkan oleh jamur dermatofita dikenal dengan istilah Tinea Unguium (Mozer, 2015).

Tujuan penelitian ini adalah untuk mengetahui hubungan lama penggunaan sepatu terhadap prevalensi jamur Trichophyton sp pada kuku pekerja tambang.

\section{METODE PENELITIAN}

Penelitian ini merupakan penelitian korelasional dengan desain univariat dengan besar sampel 40 responden yang merupakan pekerja batu bara (Kelana, 2011). Penelitian dilakukan di laboratorium parasitologi Poltekkes Kemenkes Kalimantan Timur. Responden diambil kerokan kuku kaki kemudian kerokan kuku ditanam pada media Sabaroute Dextrose Agar dan diinkubasi selama 7 hari.

\section{Alat dan bahan}

Alat yang digunakan antara lain: mikroskop, objek glass, cover glass, lampu spirtus, erlenmeyer, batang pengaduk, neraca cawan dan cawan petri. Bahan yang digunakan adalah media SDA, pewarna LPCB, kerokan kuku dan $\mathrm{NaCl} 0,9 \%$.

\section{Prosedur Kerja}

Pengujian sampel dilakukan dengan cara melakukan inkubasi kerokan kuku pada media SDA. Inkubasi dilakukan selama 7 
hari, setelah inkubasi selesai maka jamur yang tumbuh pada media diamati menggunakan mikroskop dengan pewarnaan LPCB pada perbesaran 40 kali.

Data yang diperoleh kemudian dianalisa menggunakan analisa bivariat dengan Pearson Product moment, hasil dari $\mathrm{r}$ value akan menentukan ada tidaknya korelasi antara durasi penggunaan lama sepatu safety dengan prevalensi Trichophyton sp pada penambang batu bara. $\mathrm{R}$ value menunjukkan hubungan yang signifikan jika hasilnya lebih dari 0,001 .

\section{HASIL DAN PEMBAHASAN}

Berdasarkan penelitian yang dilakukan di Laboratorium Parasitologi Jurusan Teknologi Laboratorium Medis Politeknik Kesehatan Kalimantan Timur didapatkan hasil seperti pada tabel 1.

Tabel 1. Persentase Genus Jamur pada Kuku Kaki Pekerja Tambang Batu Bara

\begin{tabular}{lcc}
\hline Genus Jamur & Frekuensi & $(\boldsymbol{\%})$ \\
\hline Trichophyton $\mathrm{sp}$ & 34 & 40,9 \\
Aspergillus $\mathrm{sp}$ & 15 & 18,1 \\
Penicillium $\mathrm{sp}$ & 15 & 18,1 \\
\hline
\end{tabular}

\begin{tabular}{lcc}
\hline Curvularia $\mathrm{sp}$ & 11 & 13,2 \\
Fusarium $\mathrm{sp}$ & 3 & 3,6 \\
Mucor $\mathrm{sp}$ & 1 & 1,2 \\
Candida $\mathrm{sp}$ & 1 & 1,2 \\
Cylindrocarpon $\mathrm{sp}$ & 2 & 2,5 \\
Cladophialophora & 1 & 1,2 \\
carrioni & & \\
\hline
\end{tabular}

Dari data pada tabel 1 diketahui infeksi jamur masing-masing sampel terdapat lebih dari satu infeksi jamur. Infeksi didominasi oleh jamur Trichophyton sp dengan persentase sebesar $40,9 \%$, terdapat pada 34 sampel. Kemudian jamur Aspergillus sp dengan persentase sebesar $18,1 \%$ terdapat pada 15 sampel, Penicillium sp dengan persentase sebesar $18,1 \%$ terdapat pada 15 sampel, Fusarium sp dengan persentase sebesar 3,6\% terdapat pada 3 sampel, Candida sp dengan persentase sebesar 1,2\% terdapat pada 1 sampel, Mucor sp dengan persentase sebesar $1,2 \%$ terdapat pada 1 sampel, Curvularia dengan persentase sebesar $13,2 \%$ terdapat pada 11 sampel, Cylindrocarpon sp dengan persentase sebesar $2,5 \%$ terdapat pada 1 sampel, Cladophialophora Carrioni dengan persentase sebesar 1,2\% terdapat pada 1 sampel.

Dari keseluruhan sampel persentase yang terinfeksi jamur Tricophyton $s p$ sebesar 85\% dari 34 sampel dan negatif Trycophyton $s p$ sebesar $15 \%$ dari 6 sampel.

Tabel 2. Hubungan Durasi Pemakaian Sepatu Safety terhadap Prevalensi Tricophyton sp pada Penambang Batu Bara

\begin{tabular}{cccccc}
\hline \multirow{2}{*}{$\begin{array}{c}\text { Durasi Penggunaan } \\
\text { Sepatu }\end{array}$} & \multicolumn{2}{c}{$\begin{array}{c}\text { Terinfeksi } \\
\text { Tricophyton } \boldsymbol{s p}\end{array}$} & \multicolumn{2}{c}{$\begin{array}{c}\text { Tidak Terinfeksi } \\
\text { Tricophyton } \boldsymbol{s} \boldsymbol{*}\end{array}$} & \multirow{2}{*}{ R value } \\
\cline { 2 - 5 } & $\mathrm{F}$ & $\%$ & $\mathrm{~F}$ & $\%$ & \\
\hline $\mathbf{2 1 2}$ jam & 34 & 0,85 & 0 & 0 & 0 \\
$\mathbf{2 - 4}$ jam & 0 & 0,00 & 6 & 15 & \\
\hline
\end{tabular}

Hubungan antara lama penggunaan sepatu boot dengan prevalensi infeksi Tricophyton $s p$ didapatkan hasil korelasi yang signifikan. Berdasarkan tabel 2, dapat disimpulkan bahwa seluruh penambang batu bara yang menggunakan sepatu safety selama 12 jam terinfeksi Tricophyton sp sedangkan penambang batu bara yang menggunakan sepatu safety kurang dari 12 jam (berkisar antara 2-4 jam) tidak terinfeksi Tricophyton $s p$. Hasil signifikansi sebesar 0,931 menunjukkan korelasi yang kuat antara durasi penggunaaan sepatu safety dengan prevalensi infeksi Tricophyton $s p$ (hasil dianggap memiliki signifikansi bila $r$ value sebesar lebih dari 0,001).

Berdasarkan hasil penelitian, setelah dilakukan pemeriksaan secara makroskopis dan mikroskopis didapatkan 34 sampel yang positif terinfeksi jamur genus Trichophyton $\mathrm{sp}$. 6 sampel yang lain tidak terinfeksi Trichophyton sp namun mengindikasikan adanya jenis jamur lain seperti Penicillium sp, Aspergillus sp, Fusarium sp, Cladiophora sp, 
Cylindrocapon sp, Mucor sp, dan Curvularia sp.

Dari data yang diperoleh peneliti, besar prevalensi infeksi kuku yang disebabkan oleh jamur Trichophyton sp adalah sebesar 85\%. Genus Trichophyton sp merupakan genus dengan persentase tertinggi penyebab kerusakan kuku. Pernyataan tersebut sejalan dengan pernyataan (Ramos et al., 2016) yang menyatakan dalam penelitiannya bahwa jamur dengan genus Trichophyton sp merupakan jamur yang sering menyebabkan dermatofitosis. Penelitian sebelumnya dari juga menjelaskan bahwa jamur Trichophyton sp merupakan genus terbesar penyebab dermatomikosis yaitu sebesar $64 \%$. infeksi kuku sering disebabkan oleh beberapa jenis jamur, yaitu Dermatophyta terutama Trichophyton sp, Microsporum sp kadang dapat pula disebabkan oleh golongan nonDermatophyta seperti Aspergillus sp, dan yeast seperti Candida sp (Muthoharoh et al., 2017).

Terdapat lebih dari satu genus jamur pada satu sampel ditandai dengan koloni yang berbeda pada media dalam satu sampel. Hal ini dapat disebabkan karena pada satu sampel masing-masing jari kemungkinan terdapat infeksi jamur yang berbeda-beda dan tercampur saat dilakukan pengerokan kuku, hal ini sesuai dengan penelitian terdahulu (Muthoharoh et al., 2017).

Golongan jamur non-Dermatophyta yang merupakan jamur kontaminan seperti Apergillus sp, Penicillium sp, Mucor sp, dan Fusarium sp. Hal tersebut sesuai dengan teori menurut (Mamuaja et al., 2017) yaitu jamur yang dapat tumbuh dimana saja dan kapan saja jika kondisi dan nutrisi untuk pertumbuhannya terpenuhi, jamur ini juga dikenal dengan jamur saprofit. Jamur Apergillus sp masuk menginfeksi kuku dengan cara menginvasi langsung lapisan superfisial lempeng kuku. Sedangkan jamur Curvularia sp, Cylindrocarpon sp, dan Cladophialophora Carrioni merupakan salah satu genus jamur yang ditemukan di tanah dan di jaringan tanaman. Infeksi Curvularia sp pada kuku kaki kemungkinan dikarenakan sepatu yang digunakan bagian dalamnya tidak bersih sehingga memungkinkan adanya serpihan tanah di bagian dalam sepatu.

Trichophyton sp merupakan jamur dermatofita yang paling sering menimbulkan mikosis superfisial. Akibat yang ditimbulkan dari infeksi Trichophyton sp pada kuku biasanya berupa penebalan kuku dan kuku tidak bercahaya. Jamur Trichophyton menginvasi sel keratin, menerobos ke dalam epidermis dan selanjutnya akan menimbulkan reaksi peradangan atau inflamasi. Reaksi peradangan tersebut berada dia daerah kutan, yaitu lapisan kulit yang meliputi stratum korneum hingga stratum basale (Baraldi et al., 2015).

Penularan jamur Trichophyton sp pada pekerja tambang batu bara kemungkinan dikarenakan selalu menggunakan sepatu safety yang bersifat kedap udara sebagai alat pelindung diri yang wajib digunakan dalam bekerja. Dari hasil wawancara, rata-rata pekerja tambang menggunakan sepatu safety kurang lebih 12 jam setiap harinya dan bekerja di lingkungan yang gersang serta bersuhu cukup panas. Menurut (Hazlianda et al., 2017), pemakaian sepatu tertutup dengan waktu yang lama dan sering serta bertambahnya kelembapan karena keringat merupakan faktor resiko terjadinya dermatofitosis. Alasan untuk pengembangan infeksi ini yaitu kemudahan penularan dermatofit melalui alas kaki yang dipakai serta kondisi lingkungan kerja yang dapat memudahkan invasi stratum korneum. Sedangkan penularan jamur non dermatofita kemungkinan karena penularan dari alas kaki yang digunakan.

Hal ini sesuai dengan (Mamuaja et al., 2017) bahwa jamur mudah ditularkan dari barang yang melekat pada kaki, seperti pakaian serta kaos kaki yang ditumbuhi jamur. Hal tersebut sebanding dengan hasil penyajian pada Tabel 2 tentang hubungan lama penggunaan sepatu dengan prevalensi Tricopyton sp pada kuku pekerja tambang. Dimana hasil yang diperoleh menunjukkan hubungan signifikan antara lama penggunaan sepatu dengan prevalensi Tricopyton sp dengan hasil signifikansi nya sebesar 0,931. Adanya data tersebut menjadi perhatian bagi para pengguna sepatu safety dalam jangka waktu yang lama harus tetap 
memperhatikan kebersihan sepatu sehingga terhindar dari infeksi onikomikosis. Sebagai tambahan, 6 sampel yang tidak terinfeksi Tricopyton sp adalah pekerja dengan lama pemakaian 2-4 jam. Mereka adalah pekerja administrasi yang lingkungan kerjanya berbeda dengan penambang batu bara yang positif terinfeksi Tricopyton sp.

Berdasarkan hasil kuesioner, sebagian besar responden personal hygiene mereka kurang baik, mereka kurang menjaga kebersihan diri seperti tidak mencuci kaki menggunakan sabun sehabis menggunakan sepatu, tidak pernah menjemur sepatu setelah digunakan, kemudian pemakaian sepatu kedap udara dalam jangka waktu yang lama yang menyebabkan kelembaban pada kaki, serta penggunaan kaos kaki yang terkadang tidak diganti setiap harinya. Hal tersebut sejalan dengan penelitian (Mamuaja et al., 2017) yaitu faktor predisposisi penyebab terjadinya infeksi jamur yaitu kelembaban tinggi, oklusi, trauma berulang pada kuku dan penurunan imunitas. Infeksi kuku dapat tumbuh dengan waktu yang lama dan membutuhkan paparan yang sering.

Simpulan dari penelitian ini adalah terdapat hubungan yang signifikan antara lama penggunaan sepatu boot dengan prevalensi Tricophyton $s p$ hal ini ditunjukkan dengan tingginya positif Tricophyton pada hasil pemeriksaan yaitu sebesar $85 \%$.

\section{KESIMPULAN DAN SARAN}

Dari 40 sampel kuku kaki pekerja tambang ditemukan jamur penyebab Tinea unguium dari genus Trichophyton sebanyak 34 sampel dengan persentase sebesar $85 \%$. Hasil signifikansi sebesar 0,931 menunjukkan korelasi yang kuat antara durasi penggunaaan sepatu safety dengan prevalensi infeksi Tricophyton $s p$ (hasil dianggap memiliki signifikansi bila $\mathrm{r}$ value sebesar lebih dari 0,001).

Saran untuk penelitian selanjutnya adalah mengidentifikasi jamur Tricophyton $s p$ sampai pada tingkat jenis untuk mengetahui berbagai jenis Tricophyton yang menginfeksi kuku pekerja tambang.

\section{REFERENSI}

Baraldi, A., Jones, S. A., Guesné, S., Traynor, M. J., McAuley, W. J., Brown, M. B., \& Murdan, S. (2015). Human Nail Plate Modifications Induced by Onychomycosis: Implications for Topical Therapy. Pharmaceutical Research, 32(5), 1626-1633.

https://doi.org/10.1007/s11095-0141562-5

Brooks, G. F., Jawetz, M., \& Adelberg's. (2012). Medical Microbiology. Newyork : McGraw-Hill Education.

Hazlianda, C. P., Muis, K., \& Lubis, I. A. (2017). Uji Diagnostik Tinea Kruris dengan Polymerase Chain Reaction Restriction Fragmented Length Polymorphism. Periodical of Dermatology and Venereology, 29(2), 158-163.

Irianto, K. (2013). Mikrobiologi Medis. Bandung: Alfabeta.

Kelana, K. D. (2011). Metodologi Penelitian Keperawatan Panduan Melaksanakan dan Menerapkan Hasil Penelitian. Yogyakarta: Trans Info Media.

Mamuaja, E. H., Susanti, R. I., Suling, P. L., \& Kapantow, G. M. (2017). Onikomikosis Kandida yang Diterapi dengan Itrakonazol Dosis Denyut. Jurnal Biomedik (Jbm), 9(3), 178-183. https://doi.org/10.35790/jbm.9.3.2017. 17340

Mozer, H. (2015). Uji Aktivitas Antifungi Ekstrak Etanol 96\% Kulit Batang Kayu Jawa (Lannea coromandelica) Terhadap Aspergillus niger, Candida albicans, dan Trichophyton rubrum. Fakultas Kedokteran Dan Ilmu Kesehatan UIN Syarif Hidayatullah, 69(2), 283-291.

Muthoharoh, A., Kartika, S. P., \& Dewi, R. (2017). Gambaran Infeksi Tinea Pedis pada Sela Jari Kaki Pendulang Intan di Desa Waringin Tunggal RT.07 RW.04 Kecamatan Kuranji Kabupaten Tanah Bumbu Maret 2017. 93(I), 259. 
Pravitasari, N. D., Hidayatullah, Arif, T., Nuzula, A. F., \& Puspita, R. (2019). Profil Dermatofitosis Superfisialis Periode Januari - Desember 2017 Di Rumah Sakit Islam Aisiyah Malang. Saintika Medika, 15(1),

25. https://doi.org/10.22219/sm.vol15.smum $\mathrm{m} 1.8625$

Rahman, M. A. A., Jusak, \& Erwin, S. (2016). Sistem Pakar Identifikasi Penyakit Jamur Kulit Pada Manusia Menggunakan Metode Certainty. Jsika, 5(3), 1-7.
Ramos, R. R., Kozusny-Andreani, D. I., Fernandes, A. U., \& Baptista, M. da S. (2016). Photodynamic action of protoporphyrin IX derivatives on Trichophyton rubrum. Anais Brasileiros de Dermatologia, 91(2), 135-140. https://doi.org/10.1590/abd18064841.20163643 